\title{
The Analysis of the Influence Factors of IT Innovation Capability and Business Strategy Co-evolution of E-commerce Enterprises-based on System Dynamics
}

\author{
Chaogai Xue, Lili Qian, Yawen Xu, Jinku Zhou \\ School of Management Engineering, Zhengzhou University, Science Rd 100, Zhengzhou, China \\ 2435602170@qq.com,1923201614@qq.com,1005426579@qq.com
}

Keywords: IT Innovation Capacity; Employee Knowledge Absorption Ability; Business Process Management Ability; System Dynamics

\begin{abstract}
Aimed at the forming process of electronic commerce enterprise IT innovation ability, taking the enterprise IT innovation ability and the dynamic collaborative development process of business strategy as the research object, this paper studies the interactions between the impacts during the forming of IT innovation. Firstly, the factors that influence knowledge flow in the process of the dynamic matching of enterprise IT innovation capability and business strategy are analyzed. Secondly, using system dynamics, the model is established, and the interaction of factors between the enterprise IT innovation capability and business strategy in co-evolution process is discussed. Finally, the paper makes suggestions for improving the cooperation of IT innovation capability and business strategy.
\end{abstract}

knowledge flow, this process also explores how

\section{INTRODUCTION}

In the Internet age, the integration and innovation of new information technology and other industries have brought opportunities and challenges to enterprises. Companies are investing heavily in the hope of gaining a competitive edge. But it turns out that most companies' IT inputs are not proportional to output, mainly because they focus on the acquisition of easily acquired resources and ignore to combine with business requirements (Ouyang et al., 2012). Therefore, how to realize the maximization benefit of IT investment by constructing the synergy between business strategy and IT capability becomes a research hotspot.

Only by combining IT capabilities with business needs and their own resources, enterprises can acquire sustainable competitive advantage by forming heterogeneous resources. The formation of IT ability depends on the knowledge stock, and organization learning is an effective way to enlarge the stock of knowledge. It is an effective way to expand the enterprise knowledge base through organizational learning to realize the enterprise knowledge structure and the optimization, perfection and improvement of knowledge inventory. Therefore, this paper discusses the collaborative evolution of enterprise IT innovation capability and business strategy from the perspective of knowledge flow.

\section{ANALYSIS OF INFLUENCING FACTORS}

In co-evolution process for the enterprise IT innovation capability and business strategy, employees gain knowledge and experience through a variety of access, and transfer them within the enterprise, so as to form knowledge flow between employees and enhance the synergy of IT innovation capacity and business strategy (Xu et al., 2017). From the perspective of knowledge flows from the owner to the recipient, and transfers, transforms, integrates, and creates it. Therefore, this article will analyze from the following main factors:

(1) Network density

Network density is used to measure the intensity of network members' connection with each other. Its relationship features and structural characteristics affect the ability of enterprise resource acquisition, integration and release. And it is media and channels for enterprise to obtain key resources (Xie et al., 2011). The trust mechanism in high-density network can lead to faster information flow frequency between network members and easier access to each other's resources, so as to improve enterprise resource acquisition ability and the knowledge absorptive capacity. Due to the formation of trust mechanism, more tacit knowledge and detailed information can be shared between network members.

(2) Innovation intention

The innovation intention is based on "behavioral intention", which is the internal motivation to influence employees' innovation behavior. And it can lead to the difference of innovation behavior and innovation effect (Cao et al., 2016). The innovation intention with strong subjectivity will promote innovation behavior, encourage employees to involve in innovative activities actively, to take the initiative to collect all kinds of innovative information, actively develop innovative activities which all kinds of resources required, to obtain higher innovation ability. Therefore, the willingness to innovate contributes to the improvement of innovation ability.

(3) R\&D input ratio

$R \& D$ input ratio reflects the $R \& D$ input of enterprises in technology research and development, which is an important index to measure the level of R\&D investment. R\&D input can satisfy the capital requirements that the innovation activities of enterprise need. R\&D spending is one of the important input index of enterprise technology innovation activities, the improvement of R\&D expenses can stimulate enterprise to promote the efficiency of technology innovation. 
(4) IT personnel capacity

IT personnel capabilities include the business capabilities and technical capabilities of IT personnel. Among them, the business ability refers to the comprehension of IT staff to other business functions and the entire business environment, and technical ability is the ability of IT staff in terms of technical expertise, including programming, operating systems, the project life cycle management, etc (Zhang and Tian, 2011). Business capabilities help IT staff to understand business requirements, guide IT personnel to implement IT effectively in a reasonable manner, and facilitate effective collaboration between IT staff and business personnel. Technical ability is the ability of IT personnel to develop corresponding technical solutions, which can help IT personnel solve technical problems in the implementation process. The interaction of IT personnel's business capabilities and technical capabilities can enable enterprises to use IT more effectively to support and influence business, and to gain sustainable competitive advantage.

(5) Knowledge absorptive capacity of employees

Employee knowledge absorbing ability refers to the knowledge receiver to integrate the new knowledge into the original knowledge structure and store it in the knowledge system. The absorptive capacity of knowledge recipients can directly affect the ability of knowledge receivers to learn, imitate, integrate

knowledge and apply new knowledge. Business people and IT personnel in in-depth discussion and analysis of business requirements, new business knowledge can be combined with the existing knowledge, the integration of knowledge and creation, so as to develop intelligent analysis system and provide decision support data.

(6) Business process management ability

Business process management ability is through the business procedure management process, to effectively integrate all sorts of factors, such as information, resources and manpower. The organizational behavior skills for process management are embodied in it $(\mathrm{Bi}$ and $\mathrm{Xu}$, 2012). The optimization of business processes requires IT to support, and business process analysis, evaluation, and implementation need to take into account the impact of IT. In fact, the strength of process management capability determines the quality of process management. The stronger the process management capability is, the higher business process identification, control, improvement and innovation of management level will be, so as to find and solve the process problem timely, improve the efficiency of process, and meet the needs of business strategy development.

\section{SIMULATION AND RESULT ANALYSIS OF THE MODEL}

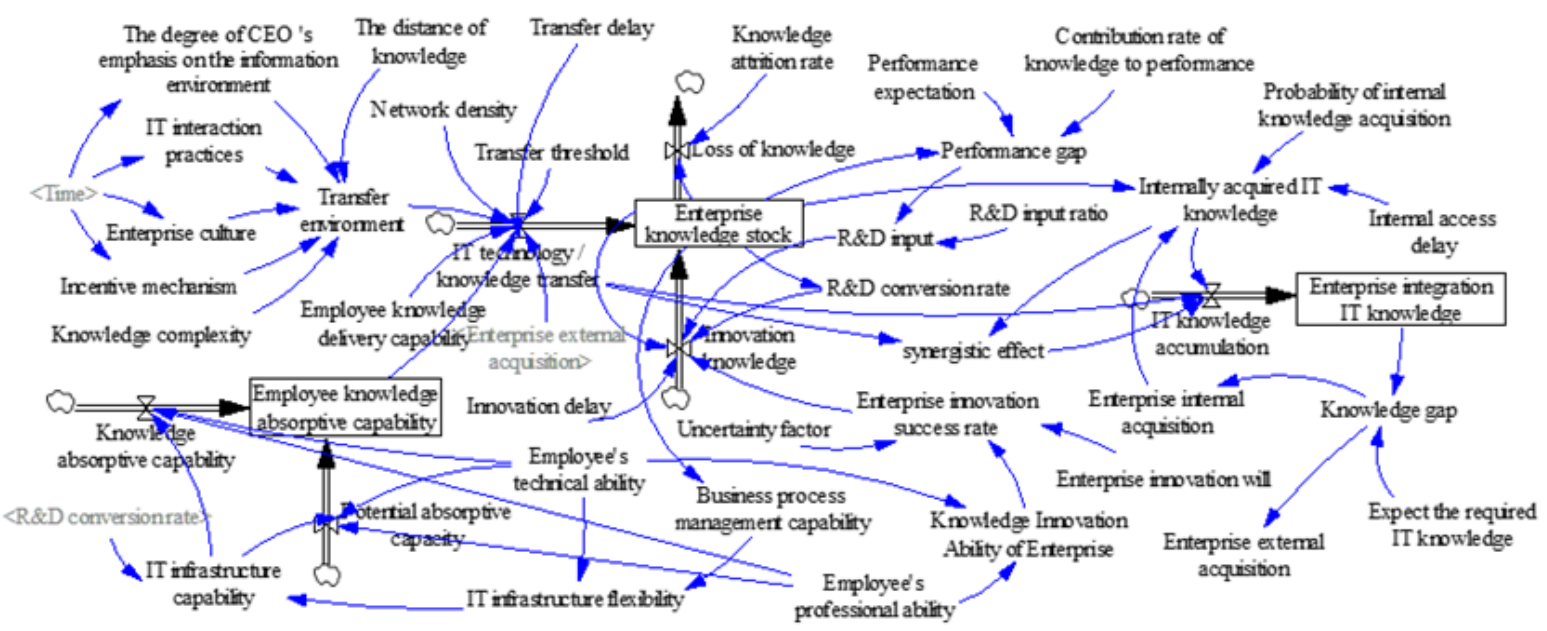

Figure 1: E-commerce enterprise IT innovation system dynamic flow diagram

(a)

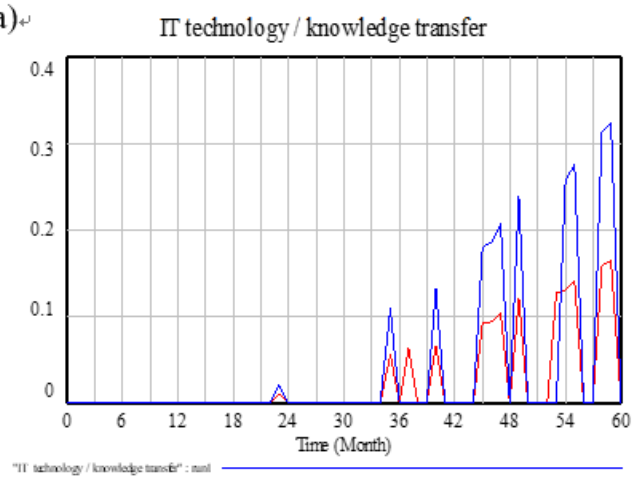

(b)

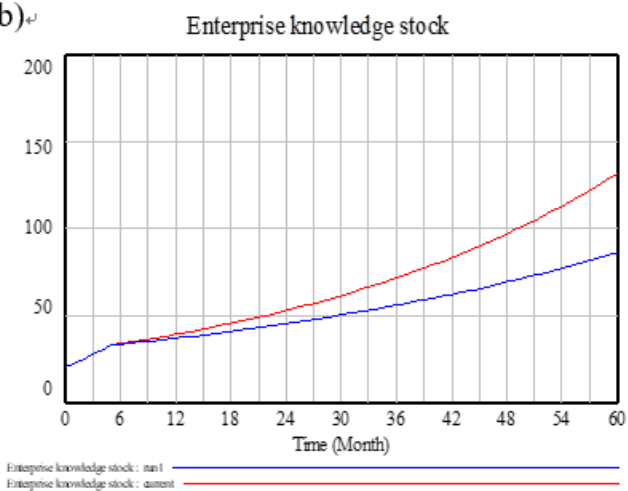

Figure 2: Variation of (a) IT technology/knowledge transfer and (b) enterprise knowledge stock caused by Network density 
Aim at enterprise IT innovation capacity and dynamic characteristics of the coordinated development of the business strategy, take the factors which influence the enterprise IT innovation ability as a whole, establish system dynamics model which can describe electronic commerce enterprise IT innovation ability, and validate the effectiveness of the model through simulation. The improvement of enterprise IT innovation ability cannot be separated from the support of enterprise knowledge stock. The change of enterprise knowledge stock originates from the transfer, innovation, integration and loss of knowledge, thus forming the flow of knowledge within the enterprise.

\subsection{Flow Diagram Construction}

On the basis of above analysis, this article from the perspective of enterprise knowledge stock changes, introduces other variables properly, establishes ecommerce enterprise IT innovation system dynamic flow diagram, as shown in figure 1.

\subsection{Parameter Sensitivity Test}

Sensitivity test is used to study the influence degree of parameter change on the system behavior, that is observing the change of model results through changing a variable within a certain range (Wu et al., 2010). In general, the change of variable value in the model will

(a)

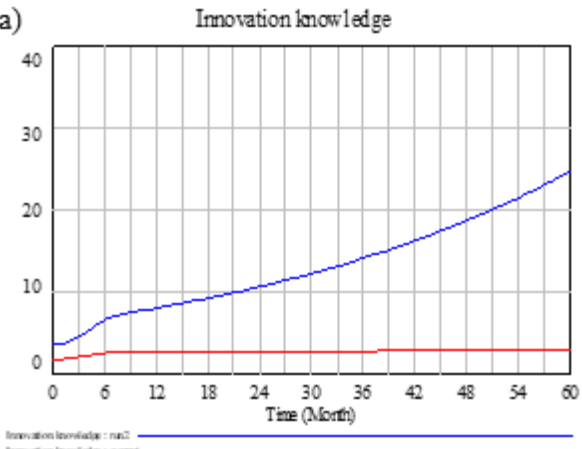

(c)

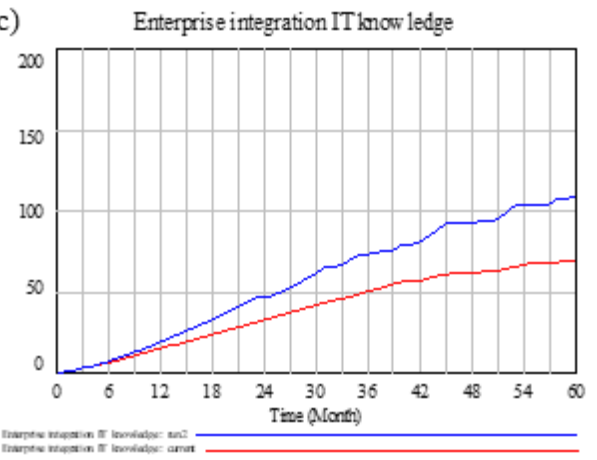

result in a certain degree of change in the output result, but the trend change should not occur, and the output results should be approximately the same. The parameters of the model are sensitive if there is a significant change in the simulated behavior curve obtained after the change of parametric equation or simulation equation in the model. In other words, the parameters of the model are not sensitive if there is no significant change in the simulated behavior curve obtained after the change of parametric equation or simulation equation in the model.

This paper tests the sensitivity of the model with the example of network density. The network density parameter values are promoted from 0.3 to 0.6 , so as to observe the change of IT technology and knowledge transfer and the stock of enterprise knowledge. The results of the simulation are shown in figure 2(a) and 2(b). It can be seen that: after the changing of network density parameter values, IT technology/knowledge transfer and the behavior of the stock of enterprise knowledge curve has differences in amplitude to some extent, but the behavior change trend of the model doesn't change much. Therefore, the system dynamics model of the enterprise IT innovation capability formed by this paper is not very strict in the requirements of the parameters, thus it is beneficial to the application of the model in practice.

(b)
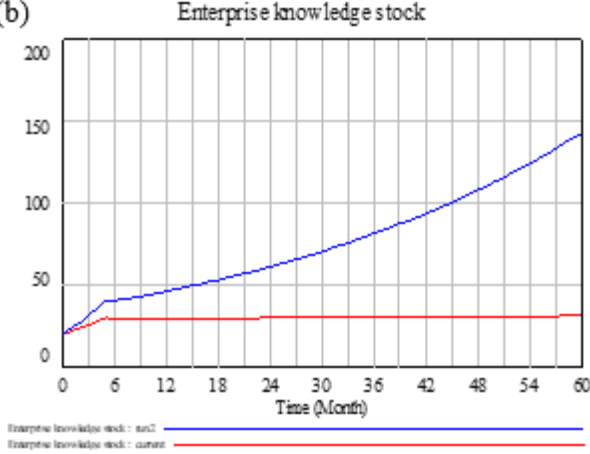

(d)

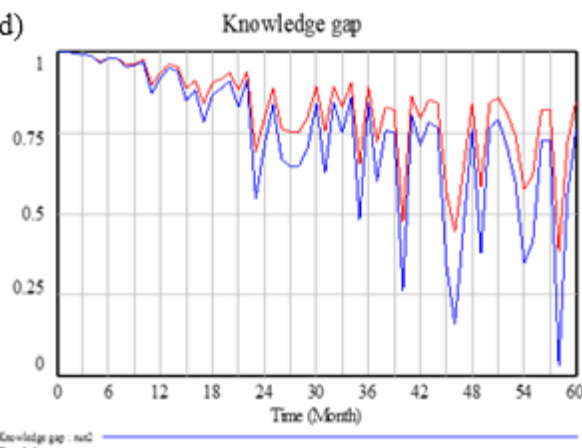

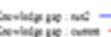

Figure 3: Variation of (a) new knowledge, (b) enterprise knowledge stock, (c) enterprise integration knowledge and (d) knowledge gap caused by innovation intention

\subsection{Application Analysis of Simulation Results}

(1) Innovation intention

The innovation intention is the intrinsic motivation of the enterprise to carry out the innovation activity, and promotes the enterprise to put the innovation plan into action, which can help to improve the innovation ability of the enterprise (Chen et al., 2014). Enterprise IT innovation will to a certain extent, affects the staff's innovation behavior, the companies with strong innovation will will encourage employees to conduct innovation activities and behavior, so as to improve enterprise IT innovation ability. The parameter of innovation intention is promoted from 0.3 to 0.6 , from 
figure 3(a) and 3(b) it can be seen that: as the enterprise innovation will enhance, the knowledge and knowledge stock of enterprise gradually increase, and present a nonlinear increasing trend. This is mainly because: the enhancement of enterprise innovation will could prompt the enterprise to implement a series of innovative measures to mobilize employees' willingness to innovate, so as to improve the staff's innovation consciousness, stimulate the staff's innovation ability and promote the realization of innovation behavior. The enhancement of employees' innovation intention will enable them to comb the existing knowledge, learn and imitate the unknown knowledge, and increase the knowledge of enterprise innovation. In the first six months, the knowledge and analysis of the existing knowledge
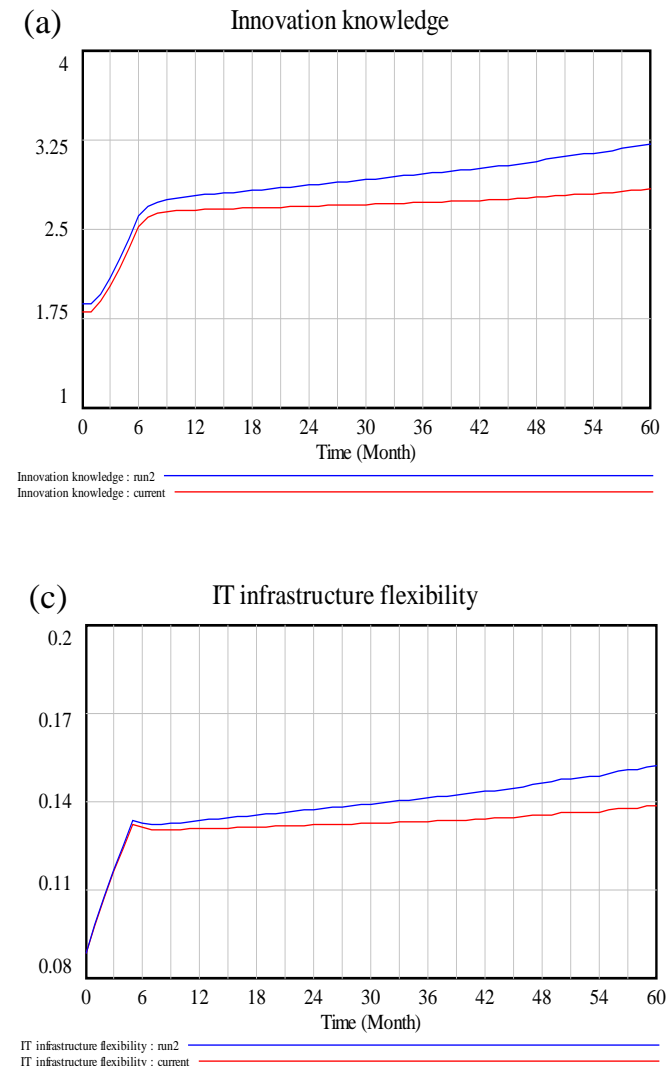

improved the speed of knowledge innovation, so the growth rate of enterprise knowledge innovation from the first to sixth month was slightly more than that from the sixth to sixtieth month. By integrating, learning and creating new knowledge, employees can improve the enterprise's IT innovation ability, reduce the knowledge gap, and realize the dynamic synergy with the business process. As shown in figure 3(c) and 3(d), the staff through the integration of internal knowledge and external knowledge learning, improve their knowledge, and through the analysis of the knowledge, imitation and creation, improve the enterprise integration utility, and reduce the knowledge gap that the improvement enterprise IT innovation ability required.
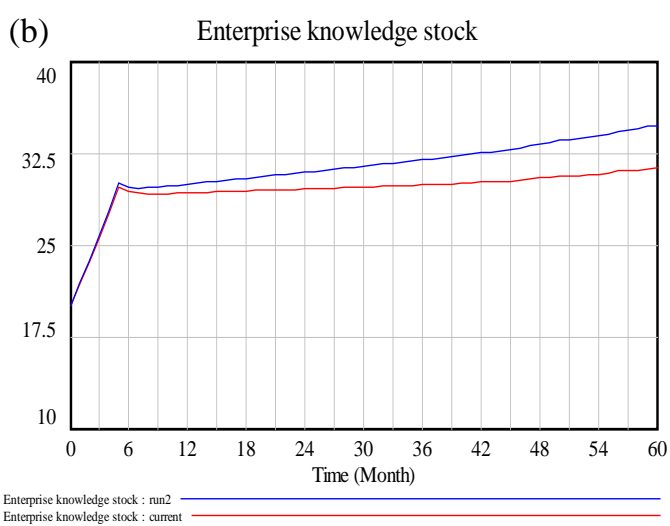

(d) Business process management capability

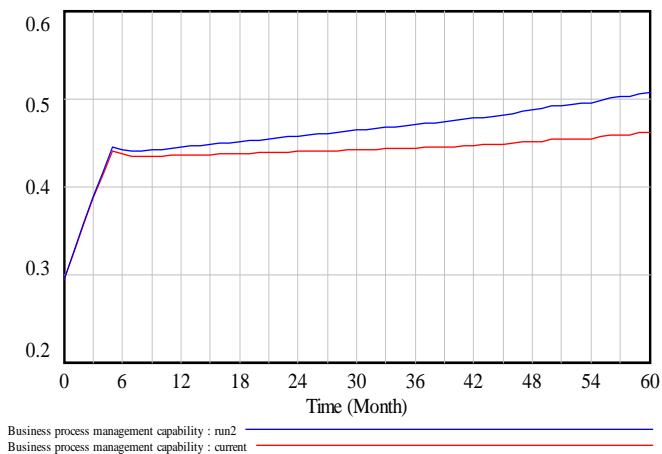

Figure 3: Variation of (a) innovation knowledge, (b) enterprise knowledge stock, (c) flexibility of IT infrastructure and (d) business process management capability caused by R\&D input

\section{(2) $R \& D$ investment ratio}

R\&D investment provides economic support for the improvement of enterprise IT innovation capability. Enterprises can use R\&D funds to supplement the IT infrastructure, human resources and intangible resources needed for their innovation activities, and meet the development needs ( $\mathrm{Li}$ et al., 2013). By buying computers, routers, switches, and other hardware, perfecting database, operating system, network planning software facilities, and improving the learning mechanism of IT and non-IT personnel, enterprises provide foundation for integrating their resources and actively introducing and absorbing the external knowledge, thus to make it easier the development of the accumulation of knowledge and innovation. The ratio of $\mathrm{R} \& \mathrm{D}$ investment is increased from 0.3 to 0.6 , as shown in figure 4(a): the intellectual quantity of enterprises presents a significant non-linear growth trend. This is mainly because the increase in $R \& D$ input effectively integrates and complements the resources, provides guarantee for the integration, introduction and creation of new knowledge. With the demand of business development, the flexibility of the enterprise IT ability to adapt to IT also gradually increases, so does the knowledge quantity of enterprise IT innovation. On the basis of the increase of innovation knowledge in the first six months, there is a certain amount of technical accumulation, so the increase rate of innovative knowledge from sixth to sixtieth months is less than that from first to sixth months. The increase of innovation knowledge enriches the enterprise knowledge base, so the enterprise knowledge stock increases gradually with 
the increase of innovation knowledge, as shown in figure 4(b). To match the business process of dynamic development, enterprises should deepen the modularity
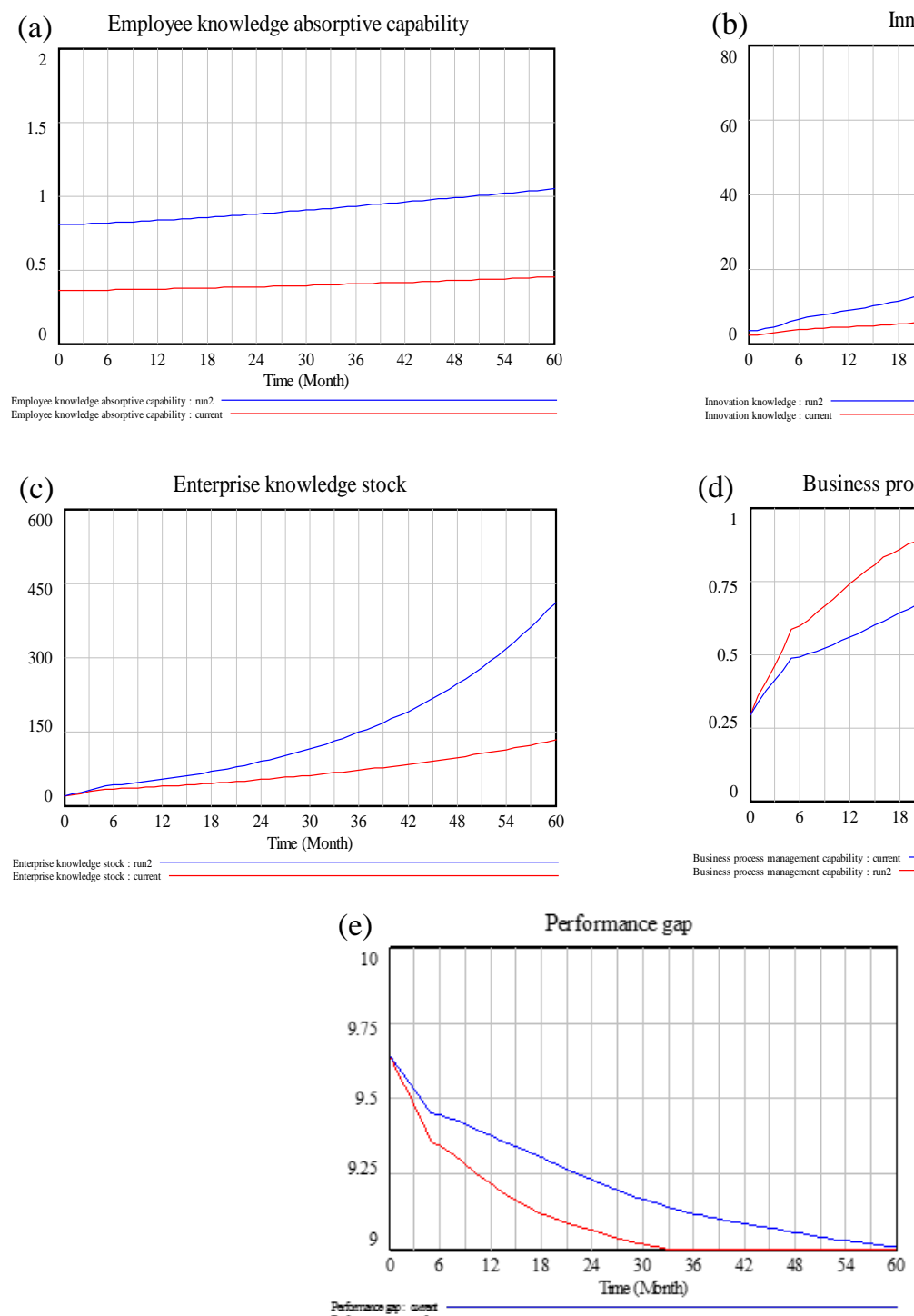

Figure 4: Variation of (a) employee knowledge absorptive capacity, (b) innovation knowledge, (c) enterprise knowledge stock, (d) business process management capability and (e) performance gap caused by business and technical ability of the IT staff

(3) Business and technical ability of IT personnel

The fundamental difference between IT department and other department is technical ability, the business ability makes IT staff understand the business better, so as to give full play to the strategic role of IT systems, subsequent synergies will enhance the business performance of the enterprise further (Bai et al., 2015). More and more enterprises start to buy universal IT software and hardware on the market, or outsource IT development projects to professional technology company, that leads to the demand for business ability of IT staff become higher and higher (Su, 2014). The business and technical ability of the IT staff are promoted from 0.3 to 0.6 , so as to improve the knowledge absorptive capacity of IT staff and enrich knowledge stock of enterprise, as shown in figure 5(a) and 5(b). Improving the business and technical ability of the IT personnel can makes the IT staff, on the basis of function of IT capability, improve the flexibility of IT infrastructure, so as to improve the management ability of the business process, as shown in figure 4(c) and 4(d).
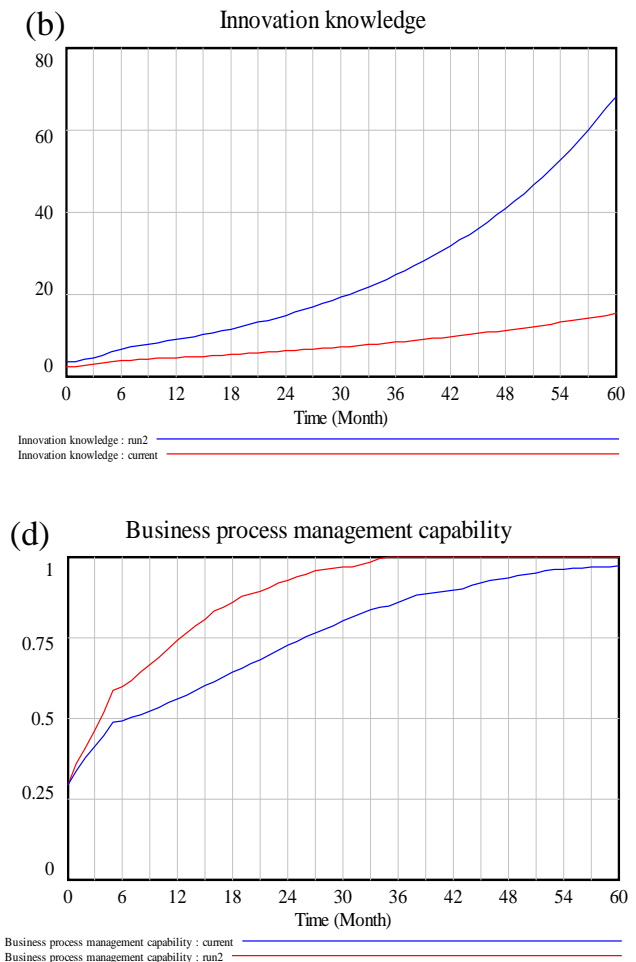

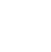


enterprise performance gap, as shown in figure 5(d).

\section{CONCLUSIONS}

This paper, using system dynamics, analyzes the main factors influence the formation of e-commerce enterprise IT innovation capacity. A model of IT innovation capacity is established and simulated by Vensim PLE. The impacts of innovation intention, R\&D investment ratio and IT personnel's business and technical ability are discussed in detail. According to the analysis results, it can be known that how to effectively use IT resources to improve employee knowledge innovation ability plays a crucial role in the process of enterprise knowledge stock. Combined with IT dynamic collaborative development process of innovation capability and business strategy, enterprise knowledge is constantly transferred, transformed, integrated and created, so as to store and update the enterprise knowledge base and provide supports for IT innovation. Hence, enterprises should pay attention to the cultivation and promotion, staff innovation will increase the intensity of R\&D investment, provide infrastructure security and multi-media learning platform, improve employee business ability and technical ability, so as to speed up the IT innovation mode, the implementation of the IT innovation ability and the business process of dynamic matching, improve enterprise competitiveness.

\section{ACKNOWLEDGEMENTS}

If any, should be placed before the references section without numbering.

\section{REFERENCES}

[1] Bing, Bai, Xiuquan, Deng, Zhiqiong, Guo and Dehua, Gao, 2015. Formation mechanism of enterprise it capability-from the perspective of the dynamic capabilities and routines, Intelligence Science. (9), pp.45-50.

[2] Chao, Su, 2014. A drive and evolution model of information technology: based on competitively strategy, resource-based vies, dynamic capabilities, Shandong University of Technology.

[3] Chuanrong, Wu, Deming, Zeng and Yingwu, Chen, 2010. Modeling and simulation of high-tech enterprises innovation networks using system dynamics, Systems Engineering Theory and Practice. 30(4), pp.587-593.

[4] Haiqing, Zhang and Jun Tian, 2011. The impact of the complementarities between business skills and technical skills of it staff on enterprise competitive advantage, Chinese Journal of Management. 8(9), pp.1259-1364.

[5] Hongming, Xie, Li, Zhao and Cong, Cheng, 2011. The research on the relationship among network density, learning capability and technological innovation, Science and technology management. 32(10), pp.57-63.

[6] Litian, Chen, Qingrui, Xu and Zhiyan, Wu, 2014. Strategic schema, innovation search and technological innovation capability evolution-theoretical modeling and simulation based on the system dynamics, Systems Engineering Theory and Practice. 34(7), pp.1705-1719.

[7] Qiudi, Li, Meiyun, Zuo and Junjie, Zhou, 2013. IT capability of electronic-commerce enterprise from CAS Theory Perspective, Journal of management. 10(9), pp.1352-1361.

[8] Taohua, Ouyang, Ling, Ding and Ruijie, Guo, 2012. Coevolution of boundary spanning and it capability: case study on haier's information system, China industrial economy. 29(12), pp.128-140.

[9] Ting, Bi and Xuefeng, Xu, 2012. Research on business process management capabilities and its influence Factors, intelligence science. 30(7), pp.999-1002.

[10] Yawen, Xu, Chaogai, Xue and Guohui, Wang, 2017. Study on the learning mechanism of enterprise IT capability based on case study: social materiality perspective, Management modernization. 37(04), pp.98-100.

[11] Yong, Cao, Zhenyu, Jiang, Helin, Sun and Qian Ruan, 2016. Knowledge spillovers, innovative intention and innovative capacity: the empirical study of strategic emerging enterprise, Studies in Science of Science. 34(1), pp.89-98. 